\title{
Placenta Previa and Placental Adhesive Diseases Does It Affect Fetal Growth Patterns?
}

\author{
Walid Mohamed Elnagar ${ }^{1 *}$ and Mai Mohamed Abdelwahab ${ }^{2}$ \\ ${ }^{1}$ Department of Obstetrics and Gynecology, Zagazig University, Egypt \\ ${ }^{2}$ Department of Pathology, Zagazig University, Egypt
}

Submission: May 20, 2019 ; Published: June 06, 2019

*Corresponding author: Walid Mohamed Elnagar, Department of Obstetrics and Gynecology, Zagazig University, Egypt

\begin{abstract}
Objective: Abnormally adherent placenta in conjunction with placenta previa not only causes bleeding issues during gestation and pregnancy but has an impact on the normal development and functions of the placenta affecting the developing fetus intra uterine. The aim of the study is to investigate the possible correlation between placentation abnormalities and fetal growth restrictive issues.
\end{abstract}

Materials and methods: A retrospective, research study of 72 research study subjects' patients having a singleton gestation diagnosed between 20 and 36 weeks of gestation with a placenta previa, both with and without placental adhesive disease.

Results: Comparative statistical analysis between adherent PAS and invasive PAS in which there was no statistical significant difference as regards maternal age ,parity, gestational age mean $+/$-SD , gestational age at delivery, delivery before 37 gestational weeks, birth weight mean $+/-$ SD birth weight below $10^{\text {th }}$ and above $90^{\text {th }}$ centiles ( $p$ values $=0.215,0.583,0.868,0.059,0.713,0.697,0.882,0.659$. There was statistical significant difference as regards EFW on sonography (centiles) ( $\mathrm{p}$ value $=0.033$ ).

Conclusions: The current research study findings have shown that, cases presenting with placenta previa without placental adhesive disease, cases having placenta previa in conjunction with placental adhesive disease are not at greater clinical risk of small for gestational age.

\section{Introduction}

Placenta previa is one of the obstetric morbid issues with increasing frequency arising due to raised rates of cesarean section deliveries all over the world. Prior cesarean section scar is a risk factor for adhesive placental disorders that gives a spectrum of bleeding issues during delivery $[1,2]$. Abnormally adherent placenta in conjunction with placenta previa not only causes bleeding issues during gestation and pregnancy but has an impact on the normal development and functions of the placenta affecting the developing fetus intra uterine [3,4]. Defective vascularization and insufficiency as regards tissue oxygenation and perfusion within the previous scar zone is correlated to local failure of re-epithelialization and decidualization which have an impact on the physiological process of implantation and placentation resulting in increased uterine artery resistance. All those changes could affect the fetal growth rates and patterns resulting in small for gestational age neonates due to greater incidence of placental vascular supply lesions [5,6]. Placenta previa coexisting with placenta accrete is well known to have morbid maternal complications. However, the influence on fetal growth and development is an area of raising research interest that must be investigated sufficiently $[7,8]$.

\section{Aim of the Work}

To investigate the possible correlation between placentation abnormalities and fetal growth restrictive issues.

\section{Materials and Methods}

A retrospective, research study of 72 research study subjects. Patients having a singleton gestation diagnosed between 20 and 36 weeks of gestation with a placenta previa, both with and without placental adhesive disease in which sonographic data and clinical outcomes were available over a 2 years period from January 2016 till February 2018 in Obstetrics and Gynecology Department, Zagazig University, Zagazig, Egypt. Exclusive research criteria involved all multiple pregnancies and coexisting medical comorbidities such as DM or hypertension with pregnancy. The fetal sonographic indices and parameters with diagnosis of abnormal placentation was diagnosed within prenatal period of gestation by a fetal medicine specialist implementing both transabdominal and transvaginal sonographic approaches. Gestations have been all dated by usage of last menstrual period and verified by crown-rump sonographic parameter before 14 gestational weeks or biparietal diameter and femur length be- 
yond $14^{\text {th }}$ gestational weeks. Hadlock formula was used for estimated fetal weight calculation and obtaining corresponding centiles. Gestational and delivery research data have been gathered from hospital recording system.

The presence and severity of any Placental adhesive disease was assessed at delivery by a consultant obstetrician and from histopathological results if a hysterectomy or a partial myometrial resection have been surgically conducted. Cases of placenta previa coexisting with placental adhesive disease have been sub categorized in accordance to villous invasiveness depth into adherent previa-PAS (clinical grade 1 or histopathological diagnosis of accreta) and invasive previa-PAS (clinical grades 2 , 3a or $3 \mathrm{~b}$ or histopathological diagnosis of increta or percreta). The study was approved by the Ethical committee of the Obstetrics and Gynecology Department, Zagazig University.

\section{Statistical Analysis}

Data were collected, revised, coded and entered to the Statistical Package for Social Science (IBM SPSS) version 23. The quantitative data were presented as mean, standard deviations and ranges when parametric and qualitative variables were presented as number and percentages. The comparison between groups regarding qualitative data was done by using Chi-square test and/or Fisher exact test when the expected count in any cell found less than 5. The comparison between two independent groups with quantitative data and parametric distribution was done by using Independent t-test. Also, the comparison between more than two independent groups with quantitative data and parametric distribution was done by using One Way ANOVA followed by post hoc analysis when significant. The confidence interval was set to $95 \%$ and the margin of error accepted was set to $5 \%$. So, the p-value was considered significant at the level of $<0.05$.

\section{Result}

Table 1 reveals and displays the correlation between the various research categorical groups (low lying placenta, placenta previa, previa with adhesive abnormalities) in which there was no statistical significance between all research categories as regards maternal age, smoking, fetal gender, Estimated fetal weight, birth weight mean \pm SD, birth weight below 10 and above 90 centiles ( $\mathrm{p}$ values $=0.539,0.921,0.972,0.723,0.756$, $0.914,0.977$ consecutively), however as regards primiparous there was statistical significant difference between research groups ( $p$ values $=0.000,0.017,0.000,0.016$ ), gestational age at diagnosis ( $\mathrm{p}$ values $=0.000$ ), gestational age at delivery ( $\mathrm{p}$ values $=0.012,0.002,0.002)$ delivery before 37 gestational weeks ( $p$ values $=0.016,0.012,0.017$ consecutively).

Table 1: Clinical characteristics of low-lying placenta, placenta previa and previa-PAS.

\begin{tabular}{|c|c|c|c|c|c|c|c|c|}
\hline & $\begin{array}{c}\text { Low Lying } \\
\text { Placenta No. }=16\end{array}$ & $\begin{array}{c}\text { Placenta Previa } \\
\text { No. }=36\end{array}$ & $\begin{array}{c}\text { Previa-PAS } \\
\text { No. }=20\end{array}$ & Test Value & P-Value & P1 & P2 & P3 \\
\hline Maternal age, Mean \pm SD & $33.15 \pm 3.4$ & $34.10 \pm 4.3$ & $34.6 \pm 3.5$ & $0.624^{*}$ & 0.539 & - & - & - \\
\hline Primiparous, no. (\%) & $11(68.75 \%)$ & $12(33.3 \%)$ & $1(5.0 \%)$ & $16.256 \bullet$ & 0 & 0.017 & 0 & 0.016 \\
\hline Fetal sex, no. (\%) & & & & $0.056 \bullet$ & 0.972 & - & - & - \\
\hline Male & $8(50.0 \%)$ & $19(52.8 \%)$ & $10(50.0 \%)$ & & & & & \\
\hline Female & $8(50.0 \%)$ & $17(47.2 \%)$ & $10(50.0 \%)$ & & & & & \\
\hline $\mathrm{GA}$ at diagnosis (weeks), mean $\pm \mathrm{SD}$ & $28.3 \pm 2.4$ & $21.7 \pm 3.5$ & $28.8 \pm 2.6$ & $45.763^{*}$ & 0 & 0 & 0.557 & 0 \\
\hline EFW on ultrasound, mean \pm SD & $43.6 \pm 5.3$ & $44.2 \pm 6.4$ & $45.1 \pm 4.4$ & $0.326^{*}$ & 0.723 & - & - & - \\
\hline GA at delivery, mean \pm SD & $37.9 \pm 2.2$ & $38.1 \pm 3.3$ & $35.8 \pm 2.1$ & $4.674^{*}$ & 0.012 & 0.826 & 0.002 & 0.002 \\
\hline Delivered < 37 weeks, no. (\%) & $3(18.75 \%)$ & $10(27.78 \%)$ & $12(60.0 \%)$ & $8.205 \bullet$ & 0.016 & 0.487 & 0.012 & 0.017 \\
\hline Birth weight, mean \pm SD & $55.1 \pm 7.6$ & $54.3 \pm 6.5$ & $53.4 \pm 6.7$ & $0.281^{*}$ & 0.756 & - & - & - \\
\hline Birth weight $<10^{\text {th }}$ centile, no. (\%) & $2(12.5 \%)$ & $5(13.89 \%)$ & $2(10.0 \%)$ & $0.178 \bullet$ & 0.914 & - & - & - \\
\hline Birth weight $>90^{\text {th }}$ centile, no. (\%) & $2(12.5 \%)$ & $5(13.89 \%)$ & $3(15.0 \%)$ & $0.046 \bullet$ & 0.977 & - & - & - \\
\hline
\end{tabular}

*: One Way ANOVA followed by post hoc analysis when significant

$\bullet$ : Chi-square test followed by multi-comparison when significant

Bold indicates significant

$\mathrm{P}$-value indicate the overall $p$-value between the three groups

P1: Post hoc analysis of Low lying plaenta vs placenta previa

P2: Post hoc analysis of Low lying plaenta vs previa-PAS

P3: Post hoc analysis of placenta previa vs previa-PAS

Table 2 reveals and displays the comparative statistical analysis as regards maternal characteristics and fetal growth parameters between low-lying placenta and placenta previa with no statistical significance as regards maternal age, parity, gestation- al age, EFW on sonography, gestational age at delivery, delivery before 37 weeks, birth weight mean +/-SD and birth weight below $10^{\text {th }}$ and above $90^{\text {th }}$ centiles ( $\mathrm{p}$ values $=0.944,0.183,0.499$, $0.922,0.859,0.232,0.652,0.624,1.000$ consecutively) 


\section{Journal of Gynecology and Women's Health}

Table 2: Comparison of maternal characteristics and fetal growth parameters between low-lying placenta $(n=15)$ and placenta previa $(n=15)$ groups matched for gestational age at delivery.

\begin{tabular}{|c|c|c|c|c|c|}
\hline & Low Lying Placenta No. $=15$ & Placenta Previa No. $=15$ & Test Value & P-Value & Sig. \\
\hline Maternal age, Mean \pm SD & $33.11 \pm 3.5$ & $33.20 \pm 3.4$ & $0.071 \bullet$ & 0.944 & NS \\
\hline Parity & $1.5 \pm 1.1$ & $2.1 \pm 1.3$ & $1.365 \bullet$ & 0.183 & NS \\
\hline GA at diagnosis (weeks), mean $\pm \mathrm{SD}$ & $28.1 \pm 2.3$ & $27.3 \pm 3.9$ & $0.684 \bullet$ & 0.499 & NS \\
\hline EFW on ultrasound, mean \pm SD & $43.4 \pm 5.1$ & $43.6 \pm 5.9$ & $0.099 \bullet$ & 0.922 & NS \\
\hline GA at delivery, mean $\pm \mathrm{SD}$ & $37.7 \pm 2.4$ & $37.9 \pm 3.6$ & $0.179 \bullet$ & 0.859 & NS \\
\hline Delivered < 37 weeks, no. (\%) & $3(20.0 \%)$ & $3(20.0 \%)$ & $1.429 *$ & 0.232 & NS \\
\hline Birth weight, mean \pm SD & $55.3 \pm 6.9$ & $56.4 \pm 6.3$ & $0.456 \bullet$ & 0.652 & NS \\
\hline Birth weight $<10^{\text {th }}$ centile, no. $(\%)$ & $2(13.3 \%)$ & $3(20.0 \%)$ & $0.240^{*}$ & 0.624 & NS \\
\hline Birth weight $>90^{\text {th }}$ centile, no. $(\%)$ & $2(13.3 \%)$ & $2(13.3 \%)$ & $0.000^{*}$ & 1 & NS \\
\hline
\end{tabular}

Table 3: Comparison of maternal characteristics and fetal growth parameters between placenta previa $(n=52)$ and previa-PAS ( $n=52)$ groups matched for smoking status and gestational age at delivery.

\begin{tabular}{|c|c|c|c|c|}
\hline & Not PAS No. = 13 & PAS No. $=13$ & Test Value & P-Value \\
\hline Maternal age, Mean $\pm S D$ & $34.31 \pm 3.69$ & $33.9 \pm 3.9$ & $0.275 \bullet$ & 0.785 \\
\hline Parity & $2.1 \pm 1.5$ & $2.2 \pm 1.8$ & $0.154 \bullet$ & 0.879 \\
\hline GA at diagnosis (weeks) , mean $\pm \mathrm{SD}$ & $22.6 \pm 3.8$ & $25.4 \pm 3.9$ & $1.854 \bullet$ & 0.076 \\
\hline EFW on ultrasound, mean \pm SD & $43.6 \pm 5.9$ & $44.8 \pm 5.3$ & $0.546 \bullet$ & 0.59 \\
\hline GA at delivery, mean \pm SD & $37.6 \pm 2.1$ & $36.7 \pm 3.1$ & $0.867 \bullet$ & 0.394 \\
\hline Delivered < 37 weeks, no. (\%) & $6(46.15 \%)$ & $6(46.15 \%)$ & $0.000^{*}$ & 1 \\
\hline Birth weight, mean \pm SD & $53.2 \pm 5.9$ & $52.7 \pm 6.2$ & $0.211 \bullet$ & 0.835 \\
\hline Birth weight $<10^{\text {th }}$ centile, no. (\%) & $2(15.4 \%)$ & $2(15.4 \%)$ & $0.000^{*}$ & 1 \\
\hline Birth weight $>90^{\text {th }}$ centile, no. (\%) & $1(7.7 \%)$ & $2(15.4 \%)$ & $0.377 \bullet$ & 0.539 \\
\hline
\end{tabular}

Table 3 reveals and displays the comparative statistical analysis as regards maternal characteristics and fetal growth parameters between placenta previa and previa placental adhesive disease in which there was no statistical significant difference between both research categorial groups as regards maternal age, parity, gestational age, EFW on sonography, gestational age at delivery, delivery before 37 weeks, birth weight mean +/-SD birth weight below 10th and above 90th centiles ( $\mathrm{p}$ values $=0.785,0.879,0.076,0.590,0.394,1.000,0.835,1.000,0.539$ consecutively )

Table 4: Comparison of maternal characteristics and fetal growth parameters between adherent previa-PAS.

\begin{tabular}{|c|c|c|c|c|c|}
\hline & Total No. $=20$ & Adherent PAS No. $=9$ & Invasive PAS No. = 11 & Test value & P-value \\
\hline Maternal age, Mean \pm SD & $34.6 \pm 3.5$ & $33.56 \pm 3.8$ & $35.57 \pm 3.2$ & $1.285 \bullet$ & 0.215 \\
\hline Parity & $2.1 \pm 1.3$ & $2.4 \pm 1.1$ & $2.5 \pm 1.15$ & $0.559 \bullet$ & 0.583 \\
\hline GA at diagnosis (weeks), mean \pm SD & $28.8 \pm 2.6$ & $28.9 \pm 2.4$ & $28.7 \pm 2.8$ & $0.169 \bullet$ & 0.868 \\
\hline EFW on ultrasound, mean $\pm \mathrm{SD}$ (centiles) & $45.1 \pm 4.4$ & $42.8 \pm 4.2$ & $47.4 \pm 4.6$ & $2.312 \bullet$ & 0.033 \\
\hline GA at delivery, mean \pm SD & $35.8 \pm 2.1$ & $34.8 \pm 1.8$ & $36.7 \pm 2.3$ & $2.020 \bullet$ & 0.059 \\
\hline Delivered < 37 weeks, no. (\%) & $12(60.0 \%)$ & $5(50.6 \%)$ & $7(63.64 \%)$ & $0.135^{*}$ & 0.713 \\
\hline Birth weight, mean \pm SD & $53.4 \pm 6.7$ & $52.8 \pm 6.3$ & $54.0 \pm 7.1$ & $0.395 \bullet$ & 0.697 \\
\hline Birth weight $<10^{\text {th }}$ centile, no. $(\%)$ & $2(10.0 \%)$ & $1(11.1 \%)$ & $1(9.1 \%)$ & $0.022^{*}$ & 0.882 \\
\hline Birth weight $>90^{\text {th }}$ centile, no. (\%) & $3(15.0 \%)$ & $1(11.1 \%)$ & $2(18.2 \%)$ & $0.194^{*}$ & 0.659 \\
\hline
\end{tabular}

Bold indicates significant

$\bullet:$ Independent t-test; *: Chi-square test

Table 4 reveals and displays the comparative statistical analysis between Adherent PAS And invasive PAS in which there was no statistical significant difference as regards maternal age, parity, gestational age mean +/-SD, gestational age at delivery, delivery before 37 gestational weeks, birth weight mean $+/-$ SD birth weight below $10^{\text {th }}$ and above $90^{\text {th }}$ centiles $(\mathrm{p}$ values $=0.215$, $0.583,0.868,0.059,0.713,0.697,0.882,0.659$. There was statis- tical significant difference as regards EFW on sonography (centiles $)(p$ value $=0.033)$

\section{Discussion}

Doppler sonographic study of the uterine circulatory system in cases having a prior caesarean delivery have revealed that uterine artery resistance is raised, and the uterine blood flow 
volume is reduced as a percentage of maternal cardiac output in comparison and contrast to cases having prior vaginal birth [8].

Various histopathologic research studies $[9,10]$. revealed at histological levels a reduced percentage of spiral artery vascular remodeling. However, in cases of invasive placental adhesive disease there is a higher remodeling level within radial/arcuate arterial systems denoting that the global maternal blood volume inflowing the placenta is raised instead of reduced $[11,12]$.

Prior research studies similar to the current research in approach and methodology have shown a low birthweight incidence under the $10^{\text {th }}$ centile in previa in conjunction with placental adhesive disease and no statistically significant difference within median neonatal birthweight between the adherent and invasive research groups denoting that histopathological changes within the spiral arteries within the area of the placenta affected by accrete area have no fetal growth pattern impact $[13,14]$.

In further most clinical scenarios, the pathologically abnormal placental adhesive disease zone is restricted to a limited number of cotyledons and therefore doesn't influence the physiologically normal adaptive placental vascular changes within the spiral arterial system located exterior the accreta zone and the physiological development and biological functional performance of the remaining placental tissue mass. Those facts could justify the current research study findings that shows great similarity to prior research study findings $[15,16]$.

Another research study priorly performed have revealed and displayed among its findings that the clinical Small for gestational age risk is not raised within placenta previa and there was no statistically significant difference as regards fetal growth patterns and indices between low-lying placenta and placenta previa and that in addition shows great harmony and similarity to the current research study findings [17].

A prior controlled research study conducted on 119 study subjects having placenta previa versus non-previa placenta matched for maternal complications, it was revealed and observed by the research group of investigators that placenta previa fetuses were statistically significantly smaller due to greater vascular lesions incidence arising from maternal reduced perfusion and to fetal thrombo-occlusive diseases than controls $[1,6]$.

Furthermore, the incidence of small for gestational age incidence below $10^{\text {th }}$ and $5^{\text {th }}$ centiles have been statistically significantly greater within the placenta previa research group. Those research findings were justified by the fact that physiological process of placentation within the uterine lower segment is correlated to suboptimal vascular development of both the utero-placental and the umbilico-placental circulations $[3,9]$.

Furthermore, interestingly a prior research like the current study have shown that placentas from gestations affected by placenta previa are observed to be smaller with elevated rate of placental weight under the $10^{\text {th }}$ centile. A prior research review has revealed and displayed that placental developmental aberrations within the maternal stromal-vascular zone cause placental dysfunction due to malperfusion and loss of structural integrity resulting in compromised fetal development besides there is elevated risk of abnormal cord insertion in comparison and contrast to controls $[5,11]$.

In harmony and great similarity to the current research a previously conducted study have shown among its findings that placenta previa is correlated and linked to small for gestational age. Fetuses as small for gestational age under the 10th centile have been independently correlated to placenta previa, adjusted $\mathrm{OR}=10.09,95 \% \mathrm{CI}=2.3-44.2$, $\mathrm{P}$ value $=0.002$. Those research findings denote a pathophysiological mal development within placenta previa gestations resulting in small for gestational age fetuses due to vascular insufficiency caused by abnormal placentation observed by placental vascular supply pathological lesions $[7,12]$.

\section{Conclusions and Recommendations}

The current research study findings have shown that, cases presenting with placenta previa without placental adhesive disease, cases having placenta previa in conjunction with placental adhesive disease are not at greater clinical risk of small for gestational age. Future research studies are recommended to be multicentric in manner and with larger sample sizes to verify the current research study findings in order to clinically innovate better management protocols for those categories of cases.

\section{References}

1. Thurn L, Lindqvist PG, Jakobsson M, Colmorn LB, Klungsoyr K, et al. (2016) Abnormally invasive placenta-prevalence, risk factors and antenatal suspicion: results from a large population-based pregnancy cohort study in the Nordic countries. BJOG 123(8): 1348-1355.

2. Kovo M, Schreiber L, Ben-Haroush A, Cohen G, Weiner E, et al. (2013) The placental factor in early- and late-onset normotensive fetal growth restriction. Placenta 34(4): 320-324.

3. Jauniaux E, Chantraine F, Silver RM, Langhoff-Roos J (2018) FIGO Placenta Accreta Diagnosis and Management Expert Consensus Panel. FIGO consensus guidelines on placenta accreta spectrum disorders: Epidemiology. Int J Gynaecol Obstet 140(3): 265-273.

4. Heidari Z, Sakhavar N, Mahmoudzadeh-Sagheb H, Ezazi-Bojnourdi T (2015) Stereological analysis of human placenta in cases of placenta previa in comparison with normally implanted controls. J Reprod Infertil 16(2): 90-95.

5. Jauniaux E, Bhide A (2017) Prenatal ultrasound diagnosis and outcome of placenta previa accreta after caesarean delivery: a systematic review and metaanalysis. Am J Obstet Gynecol 217(1): 27-36.

6. Chan JS, Baergen RN (2012) Gross umbilical cord complications are associated with placental lesions of circulatory stasis and fetal hypoxia. Pediatr Dev Pathol 15(6): 487-494.

7. Kassem GA, Alzahrani AK (2013) Maternal and neonatal outcomes of placenta previa and placenta accreta: three years of experience with a two-consultant approach. Int J Womens Health 5: 803-810.

8. Yeniel AO, Ergenoglu AM, Itil IM, Askar N, Meseri R, et al. (2012) Effect of placenta previa on fetal growth restriction and stillbirth. Arch Gynecol Obstet 286(2): 295-298. 
9. Jauniaux E, Jurkovic D (2012) Placenta accreta: pathogenesis of a 20th century iatrogenic uterine disease. Placenta 33(4): 244-251.

10. Norgaard LN, Pinborg A, Lidegaard O, Bergholt T (2012) A Danish national cohort study on neonatal outcome in singleton pregnancies with placenta previa. Acta Obstet Gynecol Scand 91(5): 546-551.

11. Rao KP, Belogolovkin V, Yankowitz J, Spinnato JA 2nd (2012) Abnormal placentation: evidence-based diagnosis and management of placenta previa, placenta accreta, and vasa previa. Obstet Gynecol Surv 67(8) 503-519.

12. Eric Jauniaux, Ivelina Dimitrova, Naomi Kenyon, Mina Mhallem, Nikos A Kametas, et al. (2019) Impact of placenta previa with placenta accreta spectrum disorder on fetal growth. Ultrasound in obstetrics \& gynecology.

13. Jauniaux E, Burton GJ (2018) Pathophysiology of placenta accreta spectrum disorders: A review of current findings. Clin Obstet Gynecol 61(4): 743-754
14. Jauniaux E, Collins SL, Burton GJ (2018) The placenta accreta spectrum: Pathophysiology and evidence-based anatomy for prenatal ultrasound imaging. Am J Obstet Gynecol 218(1): 75-87.

15. Buca D, Liberati M, Calì G, Forlani F, Caisutti C, et al. (2018) Influence of prenatal diagnosis of abnormally invasive placenta on maternal outcome: a systematic review and meta-analysis. Ultrasound Obstet Gynecol 52(3): 304-309.

16. Flo K, Widnes C, Vårtun Å, Acharya G (2014) Blood flow to the scarred gravid uterus at 22-24 weeks of gestation. BJOG 121(2): 210-215.

17. Fan D, Xia Q, Liu L, Wu S, Tian G, et al. (2017) The Incidence of Postpartum Hemorrhage in Pregnant Women with Placenta Previa: A Systematic Review and Meta-Analysis. PLoS One 12(1): e0170194.

\section{Your next submission with Juniper Publishers will reach you the below assets}

- Quality Editorial service

- Swift Peer Review

- Reprints availability

- E-prints Service

- Manuscript Podcast for convenient understanding

- Global attainment for your research

- Manuscript accessibility in different formats ( Pdf, E-pub, Full Text, Audio)

- Unceasing customer service

Track the below URL for one-step submission https://juniperpublishers.com/online-submission.php 